Bull. Chem. Soc. Ethiop. 2013, 27(2), 241-248.

ISSN 1011-3924

Printed in Ethiopia

DOI: http://dx.doi.org/10.4314/bcse.v27i2.9

(c) 2013Chemical Society of Ethiopia

\title{
SELECTIVE SODIUM REMOVAL FROM LITHIUM CHLORIDE BRINE WITH NOVEL INORGANIC ION EXCHANGER
}

\author{
Jianzhi Sun ${ }^{*}$ \\ Key Laboratory of Coordination Chemistry and Functional Materials in Universities of \\ Shandong, Dezhou University, Shandong Dezhou 253023, P. R. China
}

(Received January 23, 2012; revised December 4, 2012)

\begin{abstract}
Natrium superionic conductor (NASICON) ceramics present interesting sensitive and selective properties against alkaline cations due to their structure. The powder of $\mathrm{Li}_{1.4} \mathrm{La}_{0.4} \mathrm{Zr}_{1.6}\left(\mathrm{PO}_{4}\right)_{3}$ has been synthesized by a solid phase reaction. The removal of sodium was studied in an extensive series of tests involving different ionic exchange process variables such as time and temperature. The results indicated that its exchange capacity is very high, even reach $41.3 \mathrm{mg} / \mathrm{g}$. The $\mathrm{Na} / \mathrm{Li}$ ion exchange reaction rate increased obviously with increasing temperature, and the kinetic data fitted well to the equation of Johnson-Mehl-Avrami-Kolmogorov with a regression coefficient value of above 0.99 .
\end{abstract}

KEY WORDS: Brine, Lithium chloride, Sodium, Separation

\section{INTRODUCTION}

Lithium chloride is an industrial raw material, which can be used to produce lithium compounds and in particular metallic lithium. The presence of very small quantities of sodium in the lithium metal will make it highly reactive and much different in properties than lithium metal with high purity. So as the raw material of lithium chloride it is required in low content of sodium [1-3]. The economic and efficient further processing of the lithium chloride is necessary to provide the raw material as pure as possible.

There is a great reserve of salt lake resources in China, from which relatively low-cost crude lithium chloride can be obtained [4]. The aim of the present work is to prepare high purity lithium chloride from such feedstock.

Some special methods, such as the solvent extraction method, the cooling method and the ion exchange resins method, can be used to prepare high purity lithium chloride, depending on the properties of the feedstock [5]. All aforementioned methods for yielding lithium from natural brines or mixtures of alkali and alkaline earth metal salts involve difficult or expensive separations, and have not, in general, provided lithium products of sufficient purity for use in certain industrial applications.

Various types of inorganic and organic ion exchangers have been synthesized, and inorganic ion exchangers generally are superior to organic resins because of their greater resistance to high temperature and high radiation [6-8]. Moreover, they have unusual selectivity for ionic species and versatility in separation sciences.

Natrium superionic conductor (NASICON) ceramics present interesting sensitive and selective properties against alkaline cations due to their structure. In the ion-covalent structure, $\mathrm{Li}^{+}$ions move from one site to another passing through bottle-necks defined by the anionic skeleton. NASICON materials are especially good candidates to determine alkaline ions concentrations in solution or to separate monovalent cations from a mixture of multivalent ions [9-14].

$\mathrm{LiZr}_{2}\left(\mathrm{PO}_{4}\right)_{3}$ has the same structure as NASICON, composed of both $\mathrm{MO}_{6}$ octahedra and $\mathrm{PO}_{4}$ tetrahedra which are linked by their corners to form a three-dimension (3D) network structure.

${ }^{*}$ Corresponding author. E-mail: jianzhisun@163.com 
The resulting structure consists of Type I (octahedral O-coordination) and Type II (10-fold Ocoordination) sites for the mobile $\mathrm{Li}$ ions to occupy. $\mathrm{Li}_{1.4} \mathrm{La}_{0.4} \mathrm{Zr}_{1.6}\left(\mathrm{PO}_{4}\right)_{3}$ (LLZP) also possesses the NASICON structure with a partial substitution $\mathrm{Zr}^{4+} \rightarrow \mathrm{La}^{3+}+\mathrm{Li}^{+}$, the $\mathrm{Li}^{+}$ions occupy the Type I and Type II sites. The occupation of Li ions at the Type II sites is favorable for the chemical stability of materials $[15,16]$.

The objectives of the present study is to determine the capacity and kinetics of $\mathrm{Na}(\mathrm{I})$ ion exchange on LLZP as a function of temperature, contact time and $\mathrm{pH}$ in industrial lithium chloride brine.

\section{EXPERIMENTAL}

Synthesis of LLZP. The powder of $\mathrm{Li}_{1.4} \mathrm{La}_{0.4} \mathrm{Zr}_{1.6}\left(\mathrm{PO}_{4}\right)_{3}$ (LLZP) has been synthesized from mixture analytical reagent-grade chemicals of lithium carbonate, zirconium oxide, lanthanum oxide and ammonium dihydrogen phosphate by solid state reaction. The mixture was thoroughly mixed by planetary ball milling and then heated in an alumina crucible at $500{ }^{\circ} \mathrm{C}$ for $2 \mathrm{~h}$ in air in order to release volatile products. The product obtained was transported to sealed stainless pots with stainless balls. The mass ratio of chemicals and balls was 1:15. Then, the high-energy mechanical milling treatment was carried out at approximately $500 \mathrm{rpm}$ at room temperature. Dense glass-ceramic pellets $(10 \mathrm{~mm}$ in diameter) were obtained by cold pressing (20 MPa) the as-prepared powders and then sintering at $1000{ }^{\circ} \mathrm{C}$ for $10 \mathrm{~h}$. The different steps of the process are summarized in Figure 1.

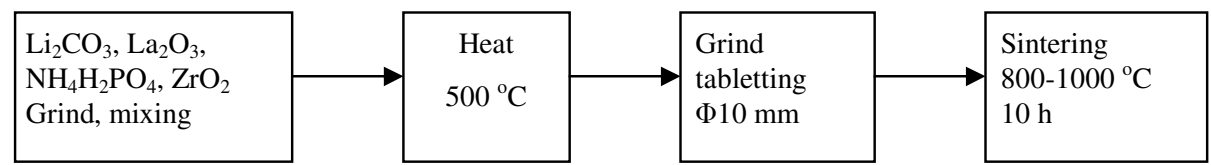

Figure 1. Synthesis of the $\mathrm{Li}_{1.4} \mathrm{La}_{0.4} \mathrm{Zr}_{1.6}\left(\mathrm{PO}_{4}\right)_{3}$ NASICON compound.

Characterization of LLZP. The powdered pattern of the sample was determined by X-ray diffraction (XRD) with $\mathrm{Cu} \mathrm{K} \alpha$ radiation ( $\lambda=0.15406 \mathrm{~nm}$ ), Rigaku D/max-3B X-ray Diffractometer. The samples were also examined for structural characteristics by Fourier transform infrared spectrophotometer, Thermo Nicolet Nexus using $\mathrm{KBr}$ pellets. The morphology of the sample was observed by scanning electron microscope (SEM), JEOL JSM$5600 \mathrm{LV}$.

Ion exchange capacity of $L L Z P$

Reagents. The crude lithium chloride brine used in this work was extracted from salt lakes brines and supplied by the Qinghai Lithium Co. Ltd. China. The chemical analyses of the feedstock are listed in Table 1.

Table 1. Impurities contents in the feedstock brine.

\begin{tabular}{|c|c|c|c|c|c|}
\hline Component & $\mathrm{LiCl}$ & $\mathrm{Na}$ & $\mathrm{Ca}$ & $\mathrm{Mg}$ & $\mathrm{SO}_{4}{ }^{2-}$ \\
\hline$\%(w / w)$ & 39.20 & 0.010 & 0.002 & 0.001 & 0.004 \\
\hline
\end{tabular}

Apparatus. Flame atomic absorption spectrophotometer (FAAS) (GBC-932 AAS, Australia) was used for determination of $\mathrm{Na}(\mathrm{I})$ ions. The FAAS was set at the optimum operating conditions at wavelength $589.6 \mathrm{~nm}$; the slit length was maintained at $0.2 \mathrm{~nm}$. All the $\mathrm{pH}$ 
measurements were performed with a calibrated $\mathrm{pH}$-meter equipped with a standard calomel electrode (SCE), Yidian·Shanghai PHS-3C. Magnetic stirrer model DF-101B (Yuying.Shanghai, voltage adjusting and temperature controlling) was used in agitating the samples at the required speeds while the centrifuge model Xiangzhi TDZ5-WS series was used for separating the residue from the solution.

Determination of the equilibrium time. $1.00 \mathrm{~g}$ of LLZP was mixed with $100 \mathrm{~g}, 39.20 \%$ (w/w) lithium chloride brine of $\mathrm{Na}(\mathrm{I})$ ions at initial concentrations of $0.010 \%(\mathrm{w} / \mathrm{w})$. The mixture was shaken constantly at a speed of $200 \mathrm{rpm}$. Aliquots were withdrawn at predetermined time intervals within a period of $200 \mathrm{~min}$. The solutions were centrifuged at a speed $3500 \mathrm{rpm}$ for 5 min and $\mathrm{Na}(\mathrm{I})$ ion concentration in the supernatant measured by FAAS.

Effect of temperature. Batch experiments were carried out using $1.00 \mathrm{~g}$ LLZP added to $100 \mathrm{~g}$, $39.20 \%(\mathrm{w} / \mathrm{w})$ lithium chloride brine at equilibrium $\mathrm{pH}$ of 7.0 and at the following temperatures: 20, 40, 60 and $80 \pm 1{ }^{\circ} \mathrm{C}$. The mixture was agitated for $200 \mathrm{~min}$ and the remaining solution was analyzed for $\mathrm{Na}(\mathrm{I})$ ions at each temperature.

Effect of pH. $1.00 \mathrm{~g}$ LLZP weighed accurately was added to $100 \mathrm{~g}, 39.20 \%$ (w/w) lithium chloride brine of $\mathrm{Na}(\mathrm{I})$ ions at initial concentrations of $0.010 \%(\mathrm{w} / \mathrm{w})$ at $80 \pm 1{ }^{\circ} \mathrm{C}$ and at $\mathrm{pH} 5.0$, $6.0,7.0,8.0$ and 9.0. The $\mathrm{pH}$ was varied from 5.0 to 9.0 by careful addition of $0.01 \mathrm{M} \mathrm{HCl}$ or $0.01 \mathrm{M} \mathrm{NaOH}$ drop wise until the desired $\mathrm{pH}$ was obtained. The mixtures were agitated for approximately $200 \mathrm{~min}$, centrifuged and the concentrations of $\mathrm{Na}(\mathrm{I})$ ions in equilibrium with LLZP determined.

Manufacturing high purity lithium chloride. The effect of varying ion exchanger mass while maintaining the concentration constant was studied as follows: $2.45,2.55$ and 2.65 g portions of the ion exchanger was placed in $100 \mathrm{~g}, 39.20 \%$ (w/w) lithium chloride brine at $80 \pm 1{ }^{\circ} \mathrm{C}$ and at $\mathrm{pH}$ 7.0. The mixture was shaken constantly at a speed of $200 \mathrm{rpm}$. After $200 \mathrm{~min}$, the solutions were centrifuged at a speed $3500 \mathrm{rpm}$ for $5 \mathrm{~min}$ and $\mathrm{Na}(\mathrm{I})$ ion concentration in the supernatant measured by FAAS.

\section{RESULTS AND DISCUSSION}

Spectroscopic studies. The result of XRD analysis shows LLZP as the major mineral constituent as seen in the spectra (Figure 2). An attempt was made to observe the change of the crystalline structure by the substitution of $\mathrm{La}^{3+}$ for $\mathrm{Zr}^{4+}$. Results showed that lanthanum has no obvious effect on the structure. The LLZP structure is indexed in the rhombohedral system with lattice: rhomb-centered, space group $\mathrm{R} \overline{3} c$ and the cell parameters: $\mathrm{a}=8.8077 \AA, \mathrm{b}=8.8077 \AA, \mathrm{c}=$ $22.715 \AA, \alpha=90^{\circ}, \beta=90^{\circ}, \gamma=120^{\circ}$. The crystalline of LLZP phase improve with the increase of heating temperature, which shows higher temperature is beneficial to the growth of the crystal.

Infrared absorption spectrum of LLZP is presented in Figure 3. There are four kinds of basic vibration modes in $\mathrm{PO}_{4}{ }^{3-}: v_{1}\left(\mathrm{~A}_{1}\right), v_{2}(\mathrm{E}), v_{3}\left(\mathrm{~F}_{2}\right)$ and $v_{4}\left(\mathrm{~F}_{2}\right)$, corresponding to the $\mathrm{PO}$ symmetric stretching vibration, $\mathrm{PO}_{2}$ symmetric bending vibration, $\mathrm{PO}$ antisymmetric stretching vibration and $\mathrm{PO}_{2}$ antisymmetric bending vibration $[17,18]$. The frequency of the broad features between 700 and $850 \mathrm{~cm}^{-1}$ in the spectrum of LLZP are somewhat lower than expected for $\mathrm{PO}_{4}{ }^{3-}$ stretching modes. In fact, bands in this region of the spectrum are often due to condensed phosphate groups such as $\mathrm{P}_{2} \mathrm{O}_{7}{ }^{4-}$ or extended polyphosphate structures. However, there are no bands near $750 \mathrm{~cm}^{-1}$ in the infrared spectrum to indicate the presence of bridging $\mathrm{P}-\mathrm{O}-\mathrm{P}$ groups. The band detected at $636.87 \mathrm{~cm}^{-1}$ is assigned to $v_{1}$. Three $v_{4}$ bands are observed in the 
infrared spectrum at $601.69,575.26$ and $557.23 \mathrm{~cm}^{-1}$, which might indicate some degree of local disordering about the $\mathrm{PO}_{4}{ }^{3-}$ anions as $\mathrm{Li}^{+}$is inserted into the compound. Infrared characteristic absorbing peaks of the groups have small change before and after ion exchange. The results are presented in Table 2. LLZP is ion exchanged with sodium ion in lithium chloride brine as follows.

$L i_{1.4} L a_{0.4} Z r_{1.6}\left(P O_{4}\right)_{3}+y N a^{+}=(1-y) L i_{1.4} L a_{0.4} Z r_{1.6}\left(P O_{4}\right)_{3}+y N a_{1.4} L a_{0.4} Z r_{1.6}\left(P O_{4}\right)_{3}+y L i^{+}$

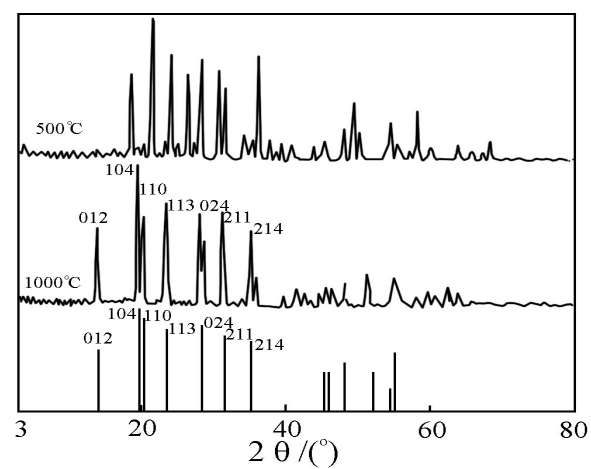

Figure 2. X-ray diffraction (XRD) scan of LLZP.

Table 2. IR data for LLZP before and after ion exchange.

\begin{tabular}{|l|l|l|l|l|}
\hline Peaks $\left(\mathrm{cm}^{-1}\right)$, before ion exchange & 636.87 & 601.69 & 575.26 & 557.23 \\
\hline Peaks $\left(\mathrm{cm}^{-1}\right)$, after ion exchange & 633.77 & 599.76 & 574.95 & 557.34 \\
\hline
\end{tabular}

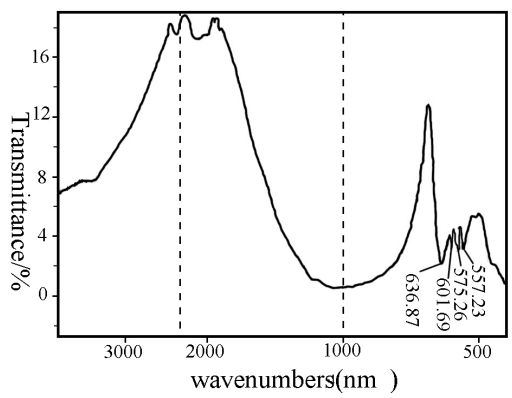

Figure 3. FTIR spectrum of LLZP.

Microstructure analysis. Figure 4 shows microstructure of the specimen. The results show that the specimen is highly dispersive particles with diameters ranged at 10-30 $\mu \mathrm{m}$. 
Selective sodium removal from lithium chloride brine with novel inorganic ion exchanger 245

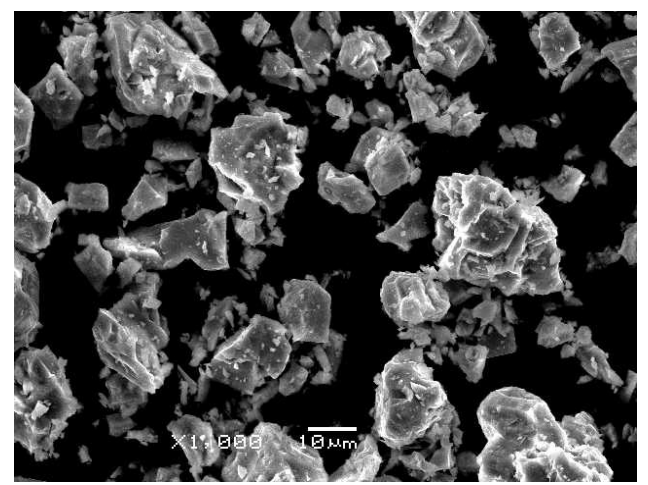

Figure 4. SEM image of LLZP.

Ion exchange capability of LLZP

Effect of contact time and temperature. The effect of contact time was evaluated for $39.20 \%$ $(\mathrm{w} / \mathrm{w})$ lithium chloride brine $\left(\mathrm{Na}^{+}: 0.010 \%(\mathrm{w} / \mathrm{w})\right)$ at different temperatures for LLZP. As shown in Figure 5, the ion-exchange capacity increases with the contact time and attains to a plateau value after $200 \mathrm{~min}$. Therefore, in all further experiments the contact time is used as 200 min. An increase in sodium removal with an increase in temperature from $20{ }^{\circ} \mathrm{C}$ to $80{ }^{\circ} \mathrm{C}$ was also observed. The diffuse rate of $\mathrm{Li}^{+}$and $\mathrm{Na}^{+}$increases with increasing temperature in lithium chloride brine, which accelerates $\mathrm{Na} / \mathrm{Li}$ ion exchange on LLZP.

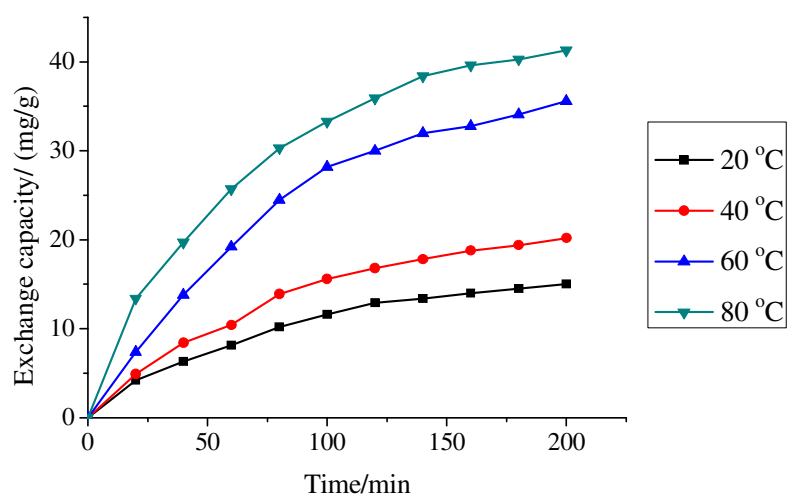

Figure 5. Influence of time on exchange capacity at $\mathrm{pH} 7.0$, agitation speed $200 \mathrm{rpm}$.

Effect of $\mathrm{pH}$. The effect of $\mathrm{pH}$ on the ion-exchange capacity of $\mathrm{Na}(\mathrm{I})$ ions is presented in Figure 6 . The exchange capacity varied between 40.57 and $41.30 \mathrm{mg} / \mathrm{g}$ when $\mathrm{pH}$ is varied between 6.0 and 9.0. Above $\mathrm{pH} 9.0$ insoluble lithium hydroxide starts to form. The exchange capacity is $35.23 \mathrm{mg} / \mathrm{g}$ at the $\mathrm{pH}$ of 5.0, this is because at low $\mathrm{pH}$ the LLZP surface is completely covered by $\mathrm{H}^{+}$increasing the competition for the available exchange sites with $\mathrm{Na}(\mathrm{I})$ ions. 


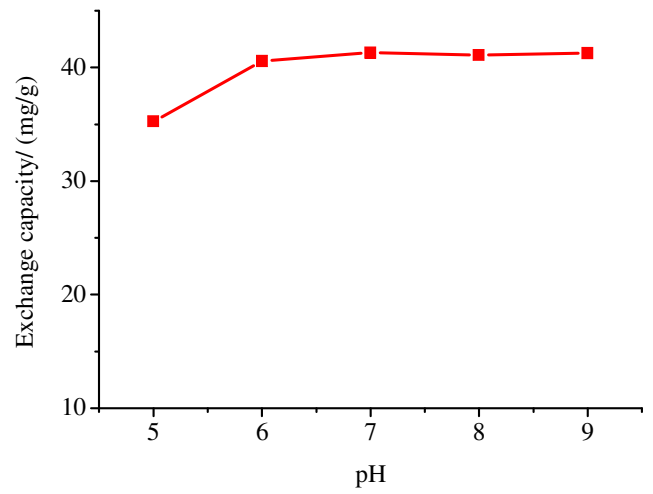

Figure 6. Effect of $\mathrm{pH}$ on the exchange capacity. Initial $\mathrm{Na}(\mathrm{I})$ ion concentration $0.01 \%(\mathrm{w} / \mathrm{w})$, ion exchanger dose $1.00 \mathrm{~g} / 100 \mathrm{~g}$, time $200 \mathrm{~min}$, agitation speed $200 \mathrm{rpm}$.

Exchange kinetics analysis. Kinetics law of $\mathrm{Na} / \mathrm{Li}$ ion exchange fraction on LLZP depends on time can be expressed using Johnson-Mehl-Avrami-Kolmogorov (JMAK) equation [19-21]. The equation may be linearized by taking the logarithm of both sides of equation 1 and linear form of JMAK equation can be given as equation 2 :

$x=1-e^{-k t^{n}}$

$\ln [-\ln (1-x)]=n \ln t+\ln k$

where $x$ is ion exchange fraction of $\mathrm{Na} / \mathrm{Li}$ on LLZP, $k$ is the dynamics constant, $t$ is the time(minute), $n$ is the time factor.

The constant values of the isotherms were obtained from the slope and intercept of the plots (Figure 7). The JMAK equation represents adequately the Kinetics law of $\mathrm{Na}^{+}$ions on LLZP.

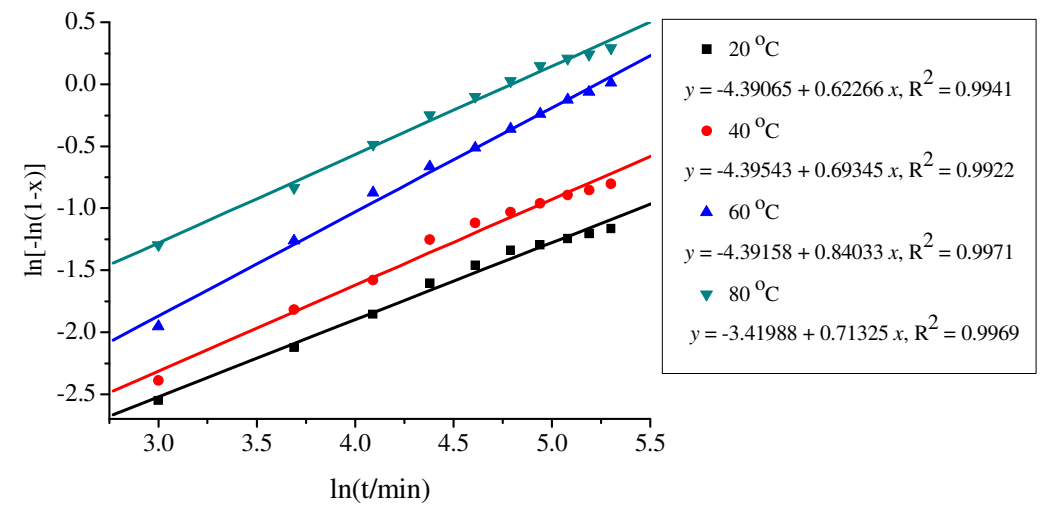

Figure 7. $\ln [-\ln (1-\mathrm{x})]$ against $\ln (\mathrm{t})$ of $\mathrm{Na} / \mathrm{Li}$ ion-exchange of LLZP.

Manufacturing high purity lithium chloride. As can be seen from the data in Table 3, LLZP exhibits favorable sodium removal from lithium chloride brine and a slight excess of ion 
exchanger can be used to ensure optimum sodium removal. Sodium concentration in the supernatant is $0.0005 \%(\mathrm{w} / \mathrm{w})$. About $95 \%$ of the sodium is removed from use of a $2.65 \mathrm{~g}$ of the exchanger in a $100 \mathrm{~g}$ of the brine.

Table 3. Ion exchange data for LLZP (initial ion concentration $0.01 \%(\mathrm{w} / \mathrm{w}), \mathrm{pH} 7.0$, time $200 \mathrm{~min}$, agitation speed $200 \mathrm{rpm}$ ).

\begin{tabular}{|l|c|c|c|}
\hline No. & $\begin{array}{c}\text { Exchanger amount, } \\
\mathrm{g}\end{array}$ & $\begin{array}{c}\text { Sodium concentration in brine, } \\
\text { Wt \% }\end{array}$ & $\begin{array}{c}\text { Percent exchange of Na(I) } \\
\text { ions, \% }\end{array}$ \\
\hline 1 & 2.45 & 0.0010 & 90.0 \\
\hline 2 & 2.55 & 0.0008 & 92.0 \\
\hline 3 & 2.65 & 0.0005 & 95.0 \\
\hline Initial LiCl brine & -- & 0.0100 & -- \\
\hline
\end{tabular}

\section{CONCLUSIONS}

The purpose of this study was to investigate the suitability of ion exchanger to separate sodium from industrial lithium chloride brine and in which brine sodium ions are not the predominant metal ions. A novel ion exchanger LLZP was synthesized and characterized using FTIR, X-ray diffraction and SEM techniques, which exhibits little change in its infrared spectra after ion exchange. The data revealed that the ion-exchange capacity was affected by the $\mathrm{pH}$ and temperature of solution. The ion exchange studies also showed that the maximum ion exchange capacity was $41.30 \mathrm{mg} / \mathrm{g}$ at a $\mathrm{pH}$ of $7.0,80{ }^{\circ} \mathrm{C}$ and the kinetics equation was nearly described by the JMAK equation. Although further investigations are needed in order to understand the ion exchange mechanism fully, the results obtained here give a fairly good idea of the ion exchange behaviour towards $\mathrm{Na}(\mathrm{I})$ ions. The high exchange capacity increases the possible practical applications in lithium chloride industries.

\section{ACKNOWLEDGEMENTS}

This work was supported by a grant from the Natural Science Foundation of Shandong (No. ZR2009FQ027) and the Technology Program of Shangdong institution of higher education (No. J09LB52).

\section{REFERENCES}

1. Syouhei, N.; Kenta, O.; Kazuharu, Y. Solvent Extr. Ion Exc. 2011, 29, 421.

2. Nakamura, E.J.; Takata, H.; Yokoyama, Y.; Miyamoto, H. U. S. Patent 20100051470, 2010.

3. Boryta, D.A.; Kullberg, T.F.; Thurston, A.M. U. S. Patent $20090214414,2009$.

4. Sun, S.Y.; Ye, F.; Song, X.F. Chin. J. Inorg. Chem. 2011, 27, 439.

5. David, B.; David, G.J.; Dan, A. U. S. Patent 20110044882, 2011.

6. Zonoza, F.M.; Ahmadi, S.J.; Nosrati, S.A.; Maraghehb, M.G. J. Hazard. Mater. 2009, 169, 808.

7. Cao, J.L.; Liu, X.W.; Fu, R.; Tan, Z.Y. Sep. Purif. Technol. 2008, 63, 92.

8. Folahan, A.A.; Nasiru, A.S.; Haleemat, I.A.; Ayomadewa, M.A.; Jacob, I.D.A. Bull. Chem. Soc. Ethiop. 2012, 26, 195.

9. Balagopal, S.; Landro, T.; Zecevic, S.; Sutija, D.; Elangovan, S.; Khandkar, A. Sep. Purif. Technol. 1999, 15, 231.

10. Puigsegur, A.; Mouazer, R.; Cretin, M.; Persin, M. Sep. Purif. Technol. 2003, 32, 51.

11. Wang, L.; Ma, W.; Liu, R.; Li, H.Y.; Meng, C.G. Solid State Ionics 2006, 177, 1421. 
12. Salkus, T.; Dindune, A.; Kanepe, Z.; Ronis, J.; Urcinskas, A.; Kezionis, A.; Orliukas, A.F. Solid State Ionics 2006, 177, 2611.

13. Liu, X.L.; Yang, L.X.; Wu, S.X.; Li, F. Chinese J. Inorg. Chem. 2012, 28, 1673.

14. Zhao, Z.W.; He, J.J.; Liu, J. J. Harbin Inst. Tech.(in Chinese) 2012, 44, 27.

15. Losilla, E.R.; Aranda, M.A.G.; Bruque, S.; Sanz, J.; París, M.A.; Campo, J.; West, A.R. Chem. Mater. 2000, 12, 2134.

16. Fuentes, R.O.; Figueiredo, F.; Marques, F.M.B.; Franco, J.I. Solid State Ionics 2001, 139, 309.

17. Xu, J.W.; Denis, F.R. Spectrochim. Acta Part A 1998, 54, 1869.

18. Burba, C.M.; Frech, R. Solid State Ionics 2006, 177, 1489.

19. Gulens, J.; Hildebrandt, B.W.; Canaday, J.D.; Kuriakose, A.K.; Weat, T.A.; Ahmad A. Solid State Ionics 1989, 35, 45.

20. Bratland, D.H.; Grong, O.; Shercliff, H.; Myhr, O.R.; Tjotta, S. Acta Mater. 1997, 45, 1.

21. Wang, M.Y.; Wang, X.W.; He, Y.H.; Lou, T.P.; Sui, Z.T. Trans. Nonferrous Met. Soc. China 2008, 18, 459. 